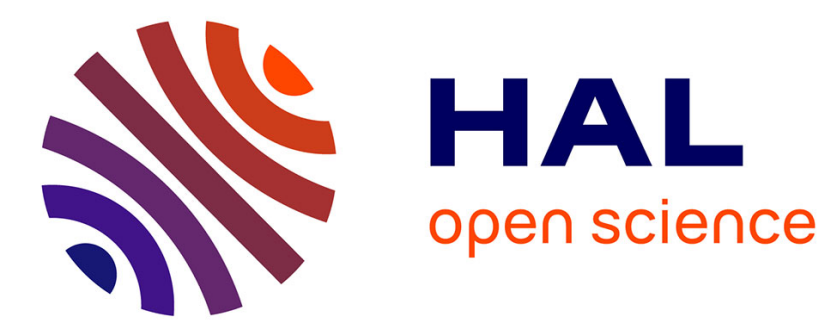

\title{
Dynamic polarity control by a tunable protein oscillator in bacteria
}

\author{
Julien Herrou, Tam Mignot
}

\section{To cite this version:}

Julien Herrou, Tam Mignot. Dynamic polarity control by a tunable protein oscillator in bacteria. Current Opinion in Cell Biology, In press, 62 (1), pp.54-60. 10.1016/j.ceb.2019.09.001 . hal-02459706

\section{HAL Id: hal-02459706 \\ https://hal-amu.archives-ouvertes.fr/hal-02459706}

Submitted on 10 Feb 2020

HAL is a multi-disciplinary open access archive for the deposit and dissemination of scientific research documents, whether they are published or not. The documents may come from teaching and research institutions in France or abroad, or from public or private research centers.
L'archive ouverte pluridisciplinaire HAL, est destinée au dépôt et à la diffusion de documents scientifiques de niveau recherche, publiés ou non, émanant des établissements d'enseignement et de recherche français ou étrangers, des laboratoires publics ou privés.

\section{(1) (1) $\$$}

Distributed under a Creative Commons Attribution - NonCommercial - NoDerivatives $\mid 4.0$ 
1 Dynamic polarity control by a tunable protein oscillator in bacteria

2

3

4

5

6

7 'Laboratoire de Chimie Bactérienne, CNRS - Aix Marseille University UMR 7283,

8 Institut de Microbiologie de la Méditerranée, Marseille, France.

9

10

11

12 Keywords: Myxococcus xanthus, MglA, MglB, RomRX, FrzX, FrzZ, oscillator,

e-mails: tmignot@imm.cnrs.fr, $\underline{\text { iherrou@imm.cnrs.fr }}$ 13 polarity, motility 


\section{Abstract}

16 In bacteria, cell polarization involves the controlled targeting of specific proteins

17 to the poles, defining polar identity and function. How a specific protein is

18 targeted to one pole and what are the processes that facilitate its dynamic

19 relocalization to the opposite pole is still unclear. The Myxococcus xanthus

20 polarization example illustrates how the dynamic and asymmetric localization of

21 polar proteins enable a controlled and fast switch of polarity. In M. xanthus, the

22 opposing polar distribution of the small GTPase MglA and its cognate activating 23 protein MglB defines the direction of movement of the cell. During a reversal 24 event, the switch of direction is triggered by the Frz chemosensory system, which 25 controls polarity reversals through a so-called gated relaxation oscillator. In this 26 review, we discuss how this genetic architecture can provoke sharp behavioral 27 transitions depending on Frz activation levels, which is central to multicellular 28 behaviors in this bacterium. 
In all three kingdoms of life, cell polarization plays an essential role in many developmental and cellular processes including molecule transport, cell shape and differentiation, cell growth and division, motility, and organelle development and localization. Cell polarity is driven by the asymmetrical distribution of proteins within a cellular compartment; this asymmetric distribution of proteins enables polarized functions by establishing a gradient of activity across a cell or the spatial confinement of an activity to a specific location. Thus, the polarization of a cell is a dynamic phenomenon, involving the active diffusion and accumulation of polarized proteins to a precise location [1-6].

Like many spatially organized organisms, bacterial cells present asymmetrically distributed polar proteins that vary widely in function. This asymmetric distribution can be dynamic over time and regulate a number of important cellular processes including cell division, DNA segregation, cell differentiation and motility etc. Specific features of the cell poles and the cell envelope facilitate protein relocalization and accumulation to these regions. Indeed, at the cell extremities, proteins can be recruited through specific interactions with polar proteins already present at the cell poles. Protein polarization can also be favored by the low chromosomal DNA density present in these regions and the curved geometry and lipid composition of the cell membrane at the poles $[2,3,6]$.

Cell polarity can be fixed and, for example, dictate the assembly and activity of specific cellular organelles, such as flagella, pili, stalks etc. [7]. In other instances, cell polarity is a dynamic process and is intimately associated with protein movement between poles. These movements can originate from the activity of biochemical oscillators. The MinCDE system, used by Escherichia coli to define the position of the division septum at mid-cell, is a good example of an oscillating protein system (Figure 1A). At one pole, MinC forms a complex with MinD, an ATPase, which associates with the membrane when bound to ATP. MinC is only active when bound to MinD; its function is to prevent FtsZ ring polymerization everywhere but the mid-cell and, thus, its polar localization prevents the formation of aberrant mini-cells. When MinE ring is recruited to the membrane by MinD, this interaction activates hydrolysis of ATP, resulting in the dissociation of the MinD cluster from the pole and the release of MinC. After binding ATP, free MinD rapidly relocates at the opposite pole, and reassociates with the MinC division inhibitor. Because of the continuous pole-to-pole oscillation of MinC and MinD, over time, the lowest concentration of MinC is at mid-cell, allowing division at the cell midpoint only, so that daughter cells are equivalent in size and shape $[3,8,9]$. In this system the oscillatory period is dictated by the slow recruitment of MinE which defines a limiting relaxation step.

The Cyanobacterial McdAB protein system is another example in which protein oscillations dictate the localization of protein complexes (Figure 1B). In Cyanobacteria, specialized compartments called carboxysomes contain essential 
enzymes for photosynthesis. In Synechococcus elongatus, McdA is an ATPase that interacts with the nucleoid in its ATP-bound form. McdB is a protein that localizes to carboxysomes and has the ability to directly stimulate McdA ATPase activity. In its ADP-bound form, McdA is released from the DNA, leading to the formation of McdA-free regions on the nucleoid. Because McdB is on the carboxysome and has the propensity to localize at regions rich in McdA, it promotes the carboxysome relocalization to those regions on the nucleoid. Thus, the carboxysomes become evenly distributed along the length of a cell. The McdA oscillations thus arise from the presence of multiple McdB-containing carboxysomes, causing McdA to repetitively dissociate from and then reassociate with the nucleoid. Hence, McdB drives emergent pole-to pole oscillatory patterning of McdA $[10,11]$.

A common feature shared by the Min and the Mcd systems is the presence of a hydrolyzable nucleotide that regulates the interaction and localization of the oscillating proteins. Thus, MinD and McdA can be considered as molecular switches that exist in an ATP-bound "ON" state and an ADP-bound "OFF" state. When bound to ATP, these proteins can form heteromers that are biologically active $[8,10,12,13]$. In both examples, gradual activation of ATPase activity controls the oscillatory period and provokes abrupt transitions in the oscillation regime.

In this review, we describe a novel type of oscillator that, similar to the two examples above, uses a nucleotide switch to regulate the oscillatory regime, but that also contains a "gate" modulating the oscillatory regime. In Myxococcus xanthus, this system controls the direction of motile cells in response to environmental cues and allows the formation of complex multicellular patterns.

\section{M. xanthus polarity switch during reversals}

M. xanthus is a Gram negative rod-shaped Deltaproteobacteria commonly found in soil and in marine sediments $[14,15]$. This organism has the ability to prey on other microorganisms and to form spores embedded in fruiting bodies when nutrients are scarce in its environment $[16,17]$. $M$. xanthus has been extensively studied for its social behavior, its complex life cycle and its motility strategies [18]. M. xanthus cells can indeed adopt a "social" motility (S-motility) or an "adventurous" motility (A-motility). During S-motility, large groups of cells move in a coordinated manner, using a form of bacterial "twitching" motility involving the so-called Type-IVa pili (T4aP) that assembles at the bacterial leading pole (Figure 2). In this process, the pili are polymerized by a multiprotein apparatus and bind like "grappling hooks" to a self-secreted exopolysaccharide. After adhesion, the pili retract by depolymerization, pulling the cell forward $[19,20]$.

During A-motility (also known as gliding motility), single cells move at the colony periphery, exploring their environment for food. Unlike S-motility, A-motility is not T4aP dependent but, instead, involves a motility machinery named Agl-Glt. This protein complex assembles at the leading pole of the cell and traffics directionally toward the lagging cell pole, attaching to the substratum thus powering the 
122 forward movement of the cell. Aglt-Glt disassembles when it reaches the lagging 123 pole (Figure 2) [20,21].

124 Therefore, $M$. xanthus presents a front-rear polarity, with the leading pole corresponding to the pole where the $\mathrm{T} 4 \mathrm{aP}$ and gliding motility apparatus assemble.

A striking feature of $M$. xanthus motility is the presence of periodic directional reversals, where cells switch direction by $180^{\circ}$ due to the inversion of cell polarity and thus redirection of pili and Agl-Glt assembly to the opposite cell pole. Regulated reversals are essential for the formation of multicellular patterns, the formation of so-called rippling waves and fruiting bodies [17,22-25].

\section{MgIA, MgIB and RomR form a biochemical oscillator}

A reversal provokes the activation of the two $M$. xanthus motility machineries at the new leading pole which is orchestrated by the small Ras-like GTPase protein MglA. MglA binds to the leading pole in its active GTP-bound form and presumably recruits key proteins of each motility systems to be assembled / activated (the exact activation mechanisms are only partially characterized and not the topic of this review) [26-29]. The polarity of MglA is controlled by two protein complexes, the newly identified RomRX system (formed by two proteins, RomR and RomX) and MgIB [26,29-31]. During reversals, the RomRX complex recruits MgIA to the new leading pole, apparently acting as a Guanine nucleotide Exchange Factor (GEF) and thus allowing MglA-GTP to bind polar effectors of the motility complexes [30]. On the other hand, binding to the lagging pole is prevented by MglB, a GTPase activating protein present at the opposite pole that converts MgIA-GTP to the inactive GDP-bound state. MgIA-GDP is diffuse in the cytoplasm and cannot interact with the poles [20]. Thus, MglA, RomRX and MglB define a polarity axis that controls the direction of movement. During reversals, MgIA relocalizes to the opposite pole, switching the polarity axis, and allowing the cells to move in the opposite direction. As further discussed below, this switch operates due to the combined action of oscillating RomRX and signal transduction (Figure $3 \mathrm{~A}$ and $\mathrm{B}$ ).

Following a reversal and the targeting of MgIA-GTP to the new leading pole (and hence activation of motility from this pole), RomRX slowly dissociates from the pole and accumulates at the lagging pole as RomR also appears to directly interact with MglB [30-32]. Remarkably, this gradual accumulation is driven by the slow dissociation of RomR, which acts as a slow pendulum for the oscillation and thus defines a typical relaxation step for the system (Figure 3A and B) [33]. The dynamics of RomR does not appear to be regulated by signal transduction and operates at the same rate, independent of the genetic background or the environmental conditions. The system reaches steady state when RomRX molecules are fully relocalized to the lagging pole, ready to recruit MgIA-GTP at this pole. However and most importantly, MgIA-GTP cannot readily relocalize to this pole, likely because the GAP activity of MglB predominates and must be 
168 inhibited for MglA to be recruited effectively by RomRX. In this situation, the 169 GATE is closed and its opening requires a signal, which is provided by the socalled Frz system.

\section{The Frz system activates the polarity switch}

The Frz chemosensory pathway is essential to trigger the polarity switch. Frz mutants are perfectly motile but are unable to reverse and consequently are blocked in rippling and fruiting body formation. The Frz system is constituted of a chemosensory-like apparatus, centrally formed by a receptor-type methyl accepting protein (FrzCD) and a cognate CheA-type histidine kinase (FrzE) $[20,32,34-39]$. The connection between Frz and MglA has long remained unclear but recently, two direct FrzE-substrate response regulators (named FrzX and FrzZ) have been shown to interact with the MglAB polarity complex [33]. FrzX acts as a phosphorylation-dependent trigger: when phosphorylated by FrzE, it binds at the lagging pole, where it has been proposed to antagonize the action of MglB [33]. Thus, the action of FrzX opens the GATE, allowing RomRX to recruit $\mathrm{MgIA}$ to the new leading pole and provoke a reversal (Figure $3 \mathrm{~A}$ and $\mathrm{B}$ ).

Reversals thus require that two threshold concentrations are reached at the lagging cell pole: [RomRX] allows efficient recruitment of MglA-GTP when MglB is efficiently antagonized by [FrzX P]. Controlling reversals this way combines the advantages of a switch and an oscillator: the RomR relaxation step causes the polarity apparatus to naturally reverse poles, whereas a gating mechanism uncouples the dynamics of RomR and the reversal switch. It follows, that at low Frz signaling levels (ie when environmental signals are not present), the cell is therefore in a poised state, fully primed for reversal and the system can rapidly switch as soon as FrzX P levels increase due to signal activation. Remarkably, at high Frz signaling levels (ie when environmental signals are persistent), $F r z X \sim P$ is in excess and the dynamics of RomR become limiting. Given that the dynamics of RomR are highly regular, the system oscillates as a typical relaxation oscillator in this regime (Figure $3 \mathrm{~A}$ and $\mathrm{B}$ ). Thus, the genetic architecture of the Frz-Mgl system allows highly adjustable responses, poised and excitable or oscillatory, depending on environmental stimulations [33].

\section{FrzZ modulates the relaxation period}

The relaxation property of RomR also implies that FrzX P-dependent stimulation is only possible if sufficient amount of RomR has accumulated at the lagging pole, which times a so-called refractory period during which no new reversal can be activated [33]. However, the relocalization of RomR is a slow process (minutes), greatly limiting the maximum reversal frequency. The FrzZ response regulator acts to limit the length of this refractory period by lowering the amount of RomR necessary at the lagging cell pole. How precisely FrzZ performs this function is unknown, but it can bind to the leading cell pole when phosphorylated and mathematical simulations suggest that FrzZ could accelerate MglA 
214 dissociation from the leading cell pole [33,40]. Thus, FrzZ acts as a rheostat, 215 tuning the refractory period in a phosphorylation-dependent manner and allowing 216 fast reversal frequencies at high signal concentrations despite the slow dynamics 217 of RomR (Figure 3A and B).

218

\section{Molecular mechanism of the polarity switch}

The exact molecular sequence of events that lead to Frz activation of the polarity switch remains to be determined. At the lagging cell pole, the accumulation of both RomRX and MgIB lead to antagonizing GAP and GEF activities. However, no accumulation of MglA is observed until FrzX accumulates at the lagging cell pole in an MglB-dependent manner. Thus, FrzX P could directly shift the balance between GAP and GEF activities in favor of the GEF and thus allow MgIA to relocalize to the lagging cell pole (Figure 4). Consistent with this, MglA and MglB co-localize at the lagging cell pole for up to $30 \mathrm{~s}$ when the switch is provoked, suggesting that during this time window, the GAP activity of MglB is no-longer efficient [33]. The mechanism by which MgIB is then relocalized to the opposite cell pole is not yet clear. Guzzo et al. [33] postulated that MglA induces the detachment of MglB, which then interacts cooperatively with itself and the membrane at the opposite pole. While this scenario is plausible, there is currently no evidence to support it and alternative mechanisms are possible. Other proteins could be involved as well, for example the MglB-like protein MglC and the PilZ-like protein PlpA $[20,41,42]$. The exact function of these proteins in the switch mechanism remains, however, mysterious. In particular, similar to MglB, $\mathrm{PlpA}$ is essential for MgIA polarity and cells bearing a $p / p A$ deletion reverse like the $m g / B$ deletion mutant [42]. Thus, PlpA and MglB might function in the same molecular pathway, which will require further investigation in the future. (Figure 4)

The mechanism by which MglA detaches from the leading cell pole is also intriguing. While it has been proposed that RomR acts as a localization factor for MglA, MglA remains stably anchored at the leading cell pole even when the most of the RomR pool has relocalized to the lagging cell pole [32]. This apparent conundrum could be explained if following its activation, MgIA-GTP interacts with other polar proteins, ie A- and S-motility effector proteins. However, it remains to be established how MglA-GTP detaches from the leading pole at the time of reversals; FrzZ P likely participates in this mechanism, but it cannot be the sole mechanism given that cells still reverse (albeit at lower frequencies) in a frz $Z$ mutant $[33,43]$. 


\section{Conclusion remarks}

In this review, we describe how a complex biochemical oscillator regulates $M$. xanthus polarity switch and its direction of movement. Because the Myxococcus polarity system incorporates a checkpoint into an oscillator, it allows excitable or oscillatory behaviors, depending on the stimulation intensity [33]. This design allows unique developmental transitions as mutants that cannot enter fast oscillations (ie the frz $Z$ mutant) are unable to form fruiting bodies, and mutants that cannot escape from oscillations are incapable to form motility swarms $[43,44]$. In the future, it will be important to determine where and when motility oscillations are exactly required during the predatory lifecycle. The molecular signals that activate the Frz pathway remain unidentified which largely complicates this analysis. Remarkably, the Frz receptor-kinase complex is not assembled in the bacterial inner membrane, as most receptors do, but it localizes to the cytoplasm, interacting directly with the nucleoid [45]. The cognate response regulators (FrzX and FrzZ) thus act as diffusible messengers between the bacterial chromosome and the cell poles. Thus, it is possible that rather than sensing extracellular cues, the Frz complex senses drastic intracellular transitions (ie metabolic) and changes as a function of global physiology. Direct coupling with the bacterial chromosome could also couple Frz (and thus cell polarity) directly with the cell cycle, potentially linking cell growth to pattern formation. In the future, it will be essential to link molecular studies in single cells to large scale pattern formation to elucidate how these regulations lead to remarkable self-organization properties.

From a broader perspective, the Frz-Mgl network likely evolved from the cooption of a bacterial chemosensory-type system (Frz) to a Ras-like polarity complex (MglA) [35]. As a result, a biochemical oscillator became tuned by a signal transduction. Given that these functional modules are broadly conserved, it is possible that similar regulations might occur in other rhythmic biological systems, converting linear regulations into oscillations (and vice-versa) as a function of stimulation intensity. Hence, the layout of the Myxococcus regulatory network could be used as a framework to facilitate the elucidation of the properties and evolution of tunable biological oscillators. 
Figure 1: Spatial oscillators control the positioning of cellular structures in bacteria.

A) The E. coli Min system positions the septal FtsZ ring at mid-cell. Pole-to-pole oscillations of MinCD ensures that the concentration of the MinC FtsZ inhibitor is minimal at mid-cell, allowing FtsZ tubulin polymerization at this site only.

B) McdB-driven intracellular oscillations of McdA position bacterial carboxysomes along the nucleoid, which here functions as a subcellular scaffold for organelle assembly.

Figure 2: Motility systems in Myxococcus xanthus.

MglA activates two motility systems at the bacterial cell pole. The S-motility system (otherwise known as twitching motility) is involved in the movement of cells in groups and involves retractile Type-IV pili that pull cells forward like grappling hooks. The A-motility system (otherwise known as gliding motility) requires the Agl-Glt complex that assembles at the leading cell pole and moves directionally toward the lagging cell pole. Propulsion is produced when moving complexes adhere to the underlying surface. Active Aglt-Glt complexes are disassembled by MglB.

Figure 3: A gated relaxation oscillator controls cell polarity switch in $M$. xanthus. A) Before a reversal, MgIA-GTP is localized at the leading pole. MglB and RomRX localize to the lagging cell pole. The cell does not reverse because the GATE is closed. When FrzE becomes active, FrzX P accumulates at the lagging cell pole and opens the GATE. The RomRX GEF complex then recruit MglA to the new leading pole and provoke a reversal. Following the reversal, RomRX slowly dissociates from the pole and accumulates at the lagging pole interacting directly with MglB. This slow process defines the relaxation step for the system and introduces a refractory period during which no new reversal can be activated. FrzZ P, which also accumulates when FrzE is active, acts to limit the length of this refractory period set by RomR.

B) Simulated profiles of MglA, MglB, RomR and FrzX P during the reversal cycle (adapted from Guzzo et al. [33]). Note that the simulation show that reversals only occur when requirements for both RomR and FrzX P are fulfilled at the lagging cell pole. Therefore, if the $[\mathrm{FrzX} \sim \mathrm{P}]$ is limiting the cell is primed and in an excitable state. On the contrary, if [FrzX P] is high the slow dynamics of RomR set the reversal period and the cell oscillates. The dashed lines indicate the time of parity of the MglB levels.

Figure 4: Molecular model of the polarity switch.

Upon activation, nucleoid-bound Frz receptor-kinase complexes phosphorylate the two diffusible response regulators FrzX and FrzZ that localize to opposite 
335 poles in their phosphorylated form. FrzX P might directly inhibit the MglB GAP 336 activity, while FrzZ P might dissociate MgIA from the pole and limit the length of 337 this refractory period set by RomR. In absence of antagonizing GAP, the RomRX 338 complex can recruit MgIA-GTP at the lagging pole. The mechanism that leads to 339 the relocalization of MglB is not clear and could require the action of other polar 340 factors such as MglC and PlpA.

341

342

343 
Conflict of interest statement

348

349

Nothing to declare

350 TM is funded by an ANR Bactocompass (ANR-15-CE13-0006)

351

352 


\section{References and recommended reading}

Papers of particular interest, published within the period of review, have been highlighted as:

*of special interest

** of outstanding interest

** Guzzo M, Murray SM, Martineau E, Lhospice S, Baronian G, My L, Zhang Y, Espinosa L, Vincentelli R, Bratton BP, Shaevitz JW, Molle V, Howard M, Mignot T. 2018. A gated relaxation oscillator mediated by FrzX controls morphogenetic movements in Myxococcus xanthus. Nat Microbiol 3:948-959. This study describes the Frz-Mgl system operating like a biochemical oscillator tuned by a signal transduction.

** Schumacher D, Sogaard-Andersen L. 2017. Regulation of Cell Polarity in Motility and Cell Division in Myxococcus xanthus. Annu Rev Microbiol 71:61-78. A comprehensive review covering recent findings regarding spatiotemporal regulation of motility and cell division in $M$. xanthus.

* Pogue CB, Zhou T, Nan B. 2018. PlpA, a PilZ-like protein, regulates directed motility of the bacterium Myxococcus xanthus. Mol Microbiol 107:214-228. This work describes a PilZ-like protein, PlpA, that localizes at the lagging cell pole in a MglB- and MglC-dependent manner. Similar to MglB, PlpA is essential for MglA polarity and cells bearing a $p / p A$ deletion reverse like a $m g / B$ deletion mutant, suggesting that PlpA and MglB function in the same molecular pathway.

** Szadkowski D, Harms A, Carreira LAM, Wigbers M, Potapova A, Wuichet K, Keilberg D, Gerland U, Sogaard-Andersen L. 2019. Spatial control of the GTPase MglA by localized RomR-RomX GEF and MgIB GAP activities enables Myxococcus xanthus motility. Nat Microbiol doi:10.1038/s41564-019-0451-4. This study describes for the first time the RomRX complex, the composite GEF of MglA.

* MacCready JS, Hakim P, Young EJ, Hu L, Liu J, Osteryoung KW, Vecchiarelli AG, Ducat DC. 2018. Protein gradients on the nucleoid position the carbon-fixing organelles of cyanobacteria. Elife 7. This study describes how carboxysomes coupled with McdB become evenly distributed along the nucleoid in Synechococcus elongates when McdA oscillates from pole-to-pole.

* Wettmann L, Kruse K. 2018. The Min-protein oscillations in Escherichia coli: an example of self-organized cellular protein waves. Philos Trans R Soc Lond B Biol Sci 373. This paper gives an overwiev of the Min-oscillating system and reviews the experimental and theoretical works that unveiled the spatio-temporal pattern emerging from interactions among the Min proteins and with the cytoplasmic membrane. 
1. Bornens M: Organelle positioning and cell polarity. Nat Rev Mol Cell Biol 2008, 9:874-886.

2. Ebersbach G, Jacobs-Wagner C: Exploration into the spatial and temporal mechanisms of bacterial polarity. Trends Microbiol 2007, 15:101-108.

3. Laloux G, Jacobs-Wagner C: How do bacteria localize proteins to the cell pole? J Cell Sci 2014, 127:11-19.

4. Rappel WJ, Edelstein-Keshet L: Mechanisms of cell polarization. Curr Opin Syst Biol 2017, 3:43-53.

5. Shapiro L, McAdams HH, Losick R: Generating and exploiting polarity in bacteria. Science 2002, 298:1942-1946.

6. Treuner-Lange A, Sogaard-Andersen L: Regulation of cell polarity in bacteria. J Cell Biol 2014, 206:7-17.

7. Kirkpatrick CL, Viollier PH: Poles apart: prokaryotic polar organelles and their spatial regulation. Cold Spring Harb Perspect Biol 2011, 3.

8. Rowlett VW, Margolin W: The bacterial Min system. Curr Biol 2013, 23:R553-556.

9. Wettmann L, Kruse K: The Min-protein oscillations in Escherichia coli: an example of self-organized cellular protein waves. Philos Trans $R$ Soc Lond B Biol Sci 2018, 373.

10. MacCready JS, Hakim P, Young EJ, Hu L, Liu J, Osteryoung KW, Vecchiarelli AG, Ducat DC: Protein gradients on the nucleoid position the carbon-fixing organelles of cyanobacteria. Elife 2018, 7.

11. Mauriello E: How bacteria arrange their organelles. Elife 2019, 8.

12. Bange G, Sinning I: SIMIBI twins in protein targeting and localization. Nat Struct Mol Biol 2013, 20:776-780.

13. Shan SO: ATPase and GTPase tangos drive intracellular protein transport. Trends Biochem Sci 2016, 41:1050-1060.

14. Brinkhoff T, Fischer D, Vollmers J, Voget S, Beardsley C, Thole S, Mussmann M, Kunze B, Wagner-Dobler I, Daniel R, et al.: Biogeography and phylogenetic diversity of a cluster of exclusively marine myxobacteria. ISME J 2012, 6:1260-1272.

15. Reichenbach H: The ecology of the myxobacteria. Environ Microbiol 1999, 1:15-21.

16. Konovalova A, Petters T, Sogaard-Andersen L: Extracellular biology of Myxococcus xanthus. FEMS Microbiol Rev 2010, 34:89-106.

17. Munoz-Dorado J, Marcos-Torres FJ, Garcia-Bravo E, Moraleda-Munoz A, Perez J: Myxobacteria: moving, killing, feeding, and surviving together. Front Microbiol 2016, 7:781.

18. Mercier R, Mignot $T$ : Regulations governing the multicellular lifestyle of Myxococcus xanthus. Curr Opin Microbiol 2016, 34:104-110.

19. Chang YW, Rettberg LA, Treuner-Lange A, Iwasa J, Sogaard-Andersen L, Jensen GJ: Architecture of the type IVa pilus machine. Science 2016, 351:aad2001. 
444

445

446

447

448

449

450

451

452

453

454

455

456

457

458

459

460

461

462

463

464

465

466

467

468

469

470

471

472

473

474

475

476

477

478

479

480

481

482

483

484

485

486

487

488

20. Schumacher D, Sogaard-Andersen L: Regulation of cell polarity in motility and cell division in Myxococcus xanthus. Annu Rev Microbiol 2017, 71:61-78.

21. Faure LM, Fiche JB, Espinosa L, Ducret A, Anantharaman V, Luciano J, Lhospice S, Islam ST, Treguier J, Sotes $M$, et al.: The mechanism of force transmission at bacterial focal adhesion complexes. Nature 2016, 539:530-535.

22. Stevens A, Sogaard-Andersen L: Making waves: pattern formation by a cell-surface-associated signal. Trends Microbiol 2005, 13:249-252.

23. Zhang H, Vaksman Z, Litwin DB, Shi P, Kaplan HB, Igoshin OA: The mechanistic basis of Myxococcus xanthus rippling behavior and its physiological role during predation. PLOS Comput Biol 2012, 8:e1002715.

24. Berleman JE, Chumley T, Cheung P, Kirby JR: Rippling is a predatory behavior in Myxococcus xanthus. J Bacteriol 2006, 188:5888-5895.

25. Thutupalli S, Sun M, Bunyak F, Palaniappan K, Shaevitz JW: Directional reversals enable Myxococcus xanthus cells to produce collective one-dimensional streams during fruiting-body formation. $J R$ Soc Interface 2015, 12:20150049.

26. Leonardy S, Miertzschke M, Bulyha I, Sperling E, Wittinghofer A, SogaardAndersen L: Regulation of dynamic polarity switching in bacteria by a Ras-like G-protein and its cognate GAP. EMBO J 2010, 29:2276-2289.

27. Mauriello EM, Mouhamar F, Nan B, Ducret A, Dai D, Zusman DR, Mignot T: Bacterial motility complexes require the actin-like protein, MreB and the Ras homologue, MgIA. EMBO J 2010, 29:315-326.

28. Treuner-Lange A, Macia E, Guzzo M, Hot E, Faure LM, Jakobczak B, Espinosa L, Alcor D, Ducret A, Keilberg D, et al.: The small G-protein MglA connects to the MreB actin cytoskeleton at bacterial focal adhesions. J Cell Biol 2015, 210:243-256.

29. Zhang Y, Franco M, Ducret A, Mignot T: A bacterial Ras-like small GTPbinding protein and its cognate GAP establish a dynamic spatial polarity axis to control directed motility. PLoS Biol 2010, 8:e1000430.

30. Szadkowski D, Harms A, Carreira LAM, Wigbers M, Potapova A, Wuichet K, Keilberg D, Gerland U, Sogaard-Andersen L: Spatial control of the GTPase MglA by localized RomR-RomX GEF and MgIB GAP activities enables Myxococcus xanthus motility. Nat Microbiol 2019.

31. Keilberg D, Wuichet $K$, Drescher $F$, Sogaard-Andersen L: A response regulator interfaces between the Frz chemosensory system and the MglA/MgIB GTPase/GAP module to regulate polarity in Myxococcus xanthus. PLoS Genet 2012, 8:e1002951.

32. Zhang $Y$, Guzzo M, Ducret $A$, Li $Y Z$, Mignot $T$ : A dynamic response regulator protein modulates G-protein-dependent polarity in the bacterium Myxococcus xanthus. PLoS Genet 2012, 8:e1002872.

33. Guzzo M, Murray SM, Martineau E, Lhospice S, Baronian G, My L, Zhang Y, Espinosa L, Vincentelli $\mathrm{R}$, Bratton $\mathrm{BP}$, et al.: $\mathbf{A}$ gated relaxation 
34. Eckhert E, Rangamani P, Davis AE, Oster G, Berleman JE: Dual oscillator mediated by FrzX controls morphogenetic movements in Myxococcus xanthus. Nat Microbiol 2018, 3:948-959. biochemical oscillators may control cellular reversals in Myxococcus xanthus. Biophys J 2014, 107:2700-2711.

35. Guzzo M, Agrebi R, Espinosa L, Baronian G, Molle V, Mauriello EM, Brochier-Armanet $C$, Mignot $T$ : Evolution and design governing signal precision and amplification in a bacterial chemosensory pathway. PLoS Genet 2015, 11:e1005460.

36. Igoshin OA, Goldbeter A, Kaiser D, Oster G: A biochemical oscillator explains several aspects of Myxococcus xanthus behavior during development. Proc Natl Acad Sci U S A 2004, 101:15760-15765.

37. Kaimer C, Berleman JE, Zusman DR: Chemosensory signaling controls motility and subcellular polarity in Myxococcus xanthus. Curr Opin Microbiol 2012, 15:751-757.

38. Kaiser D, Warrick H: Myxococcus xanthus swarms are driven by growth and regulated by a pacemaker. $J$ Bacteriol 2011, 193:5898-5904.

39. Kaimer C, Zusman DR: Regulation of cell reversal frequency in Myxococcus xanthus requires the balanced activity of CheY-like domains in FrzE and FrzZ. Mol Microbiol 2016, 100:379-395.

40. Kaimer C, Zusman DR: Phosphorylation-dependent localization of the response regulator FrzZ signals cell reversals in Myxococcus xanthus. Mol Microbiol 2013, 88:740-753.

41. McLoon AL, Wuichet K, Hasler M, Keilberg D, Szadkowski D, SogaardAndersen L: MgIC, a paralog of Myxococcus xanthus GTPaseactivating protein MgIB, plays a divergent role in motility regulation. $J$ Bacteriol 2016, 198:510-520.

42. Pogue CB, Zhou T, Nan B: PIpA, a PilZ-like protein, regulates directed motility of the bacterium Myxococcus xanthus. Mol Microbiol 2018, 107:214-228.

43. Bustamante VH, Martinez-Flores I, Vlamakis HC, Zusman DR: Analysis of the Frz signal transduction system of Myxococcus xanthus shows the importance of the conserved C-terminal region of the cytoplasmic chemoreceptor FrzCD in sensing signals. Mol Microbiol 2004, 53:1501-1513.

44. Zusman DR: "Frizzy" mutants: a new class of aggregation-defective developmental mutants of Myxococcus xanthus. J Bacteriol 1982, 150:1430-1437.

45. Moine A, Espinosa L, Martineau E, Yaikhomba M, Jazleena PJ, Byrne D, Biondi EG, Notomista E, Brilli M, Molle V, et al.: The nucleoid as a scaffold for the assembly of bacterial signaling complexes. PLOS Genet 2017, 13:e1007103. 
535 Figure 1

536
A FtsZ assembly
tsZ assembly

B
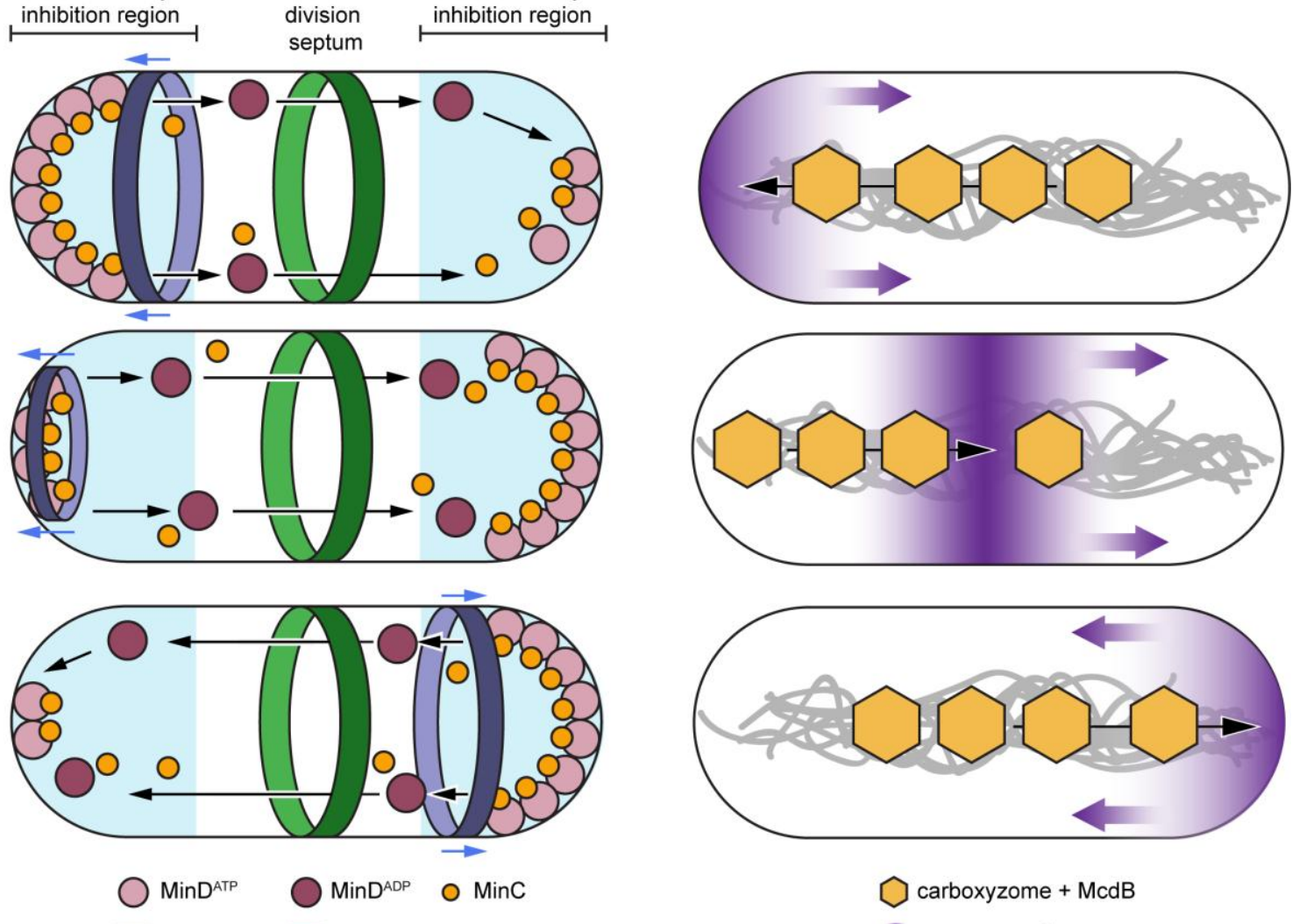

537

$\square$ MinE ring $\square$ FtsZ ring

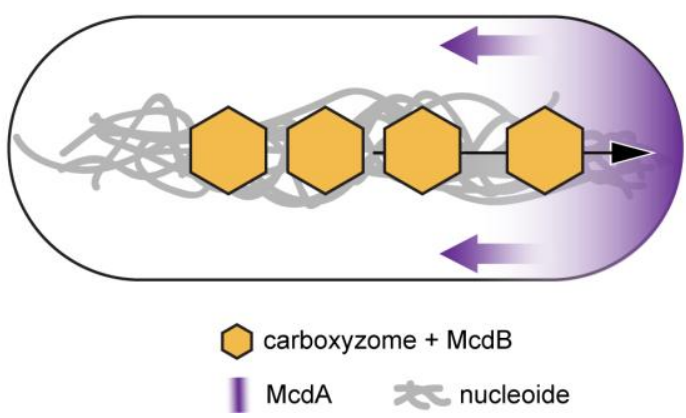

538

539 
Figure 2

\section{S-motility}

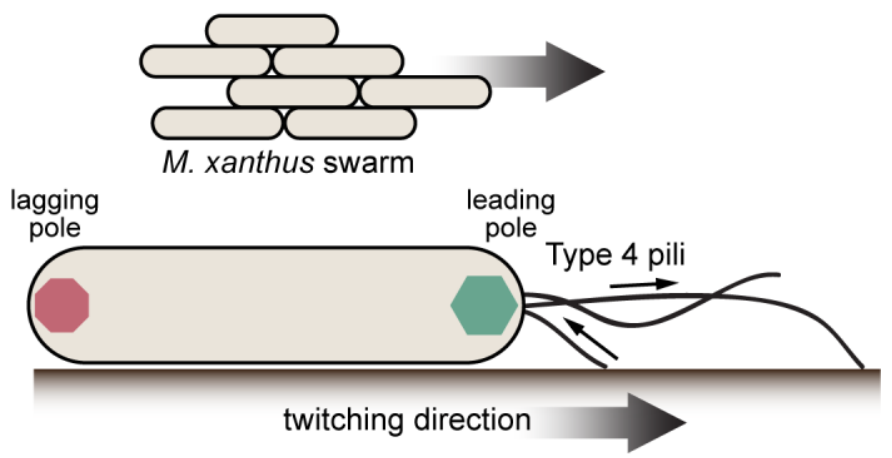

\section{A-motility}
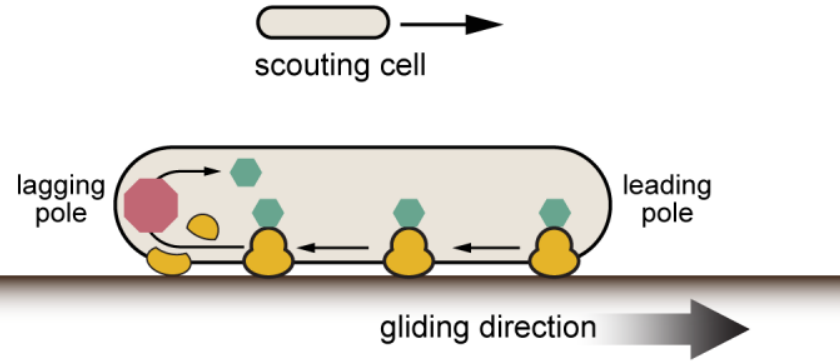

543

544

$$
\text { MglB MglA } \bigcirc \text { Agl-Glt }
$$

545 
$546 \quad$ Figure 3

547

A
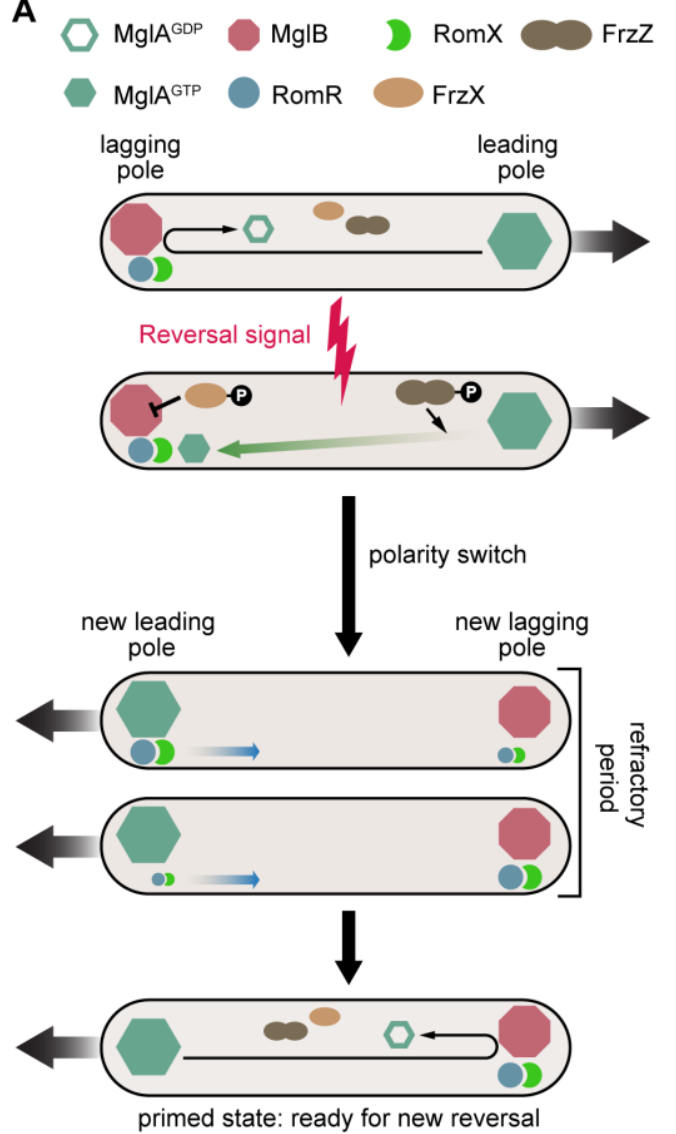

B

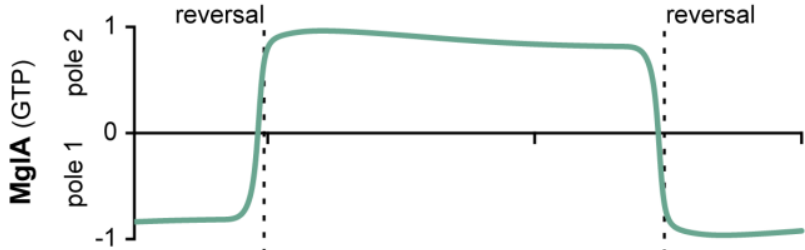

$\frac{\mathfrak{m}}{\Sigma}$

$\frac{0}{\circ}$

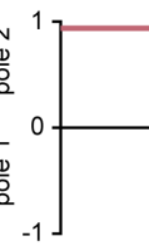

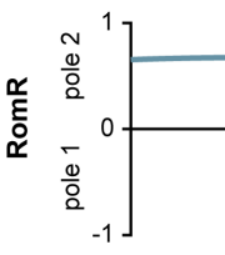

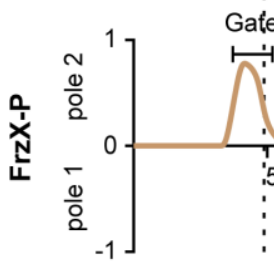

548 
Figure 4

552

553

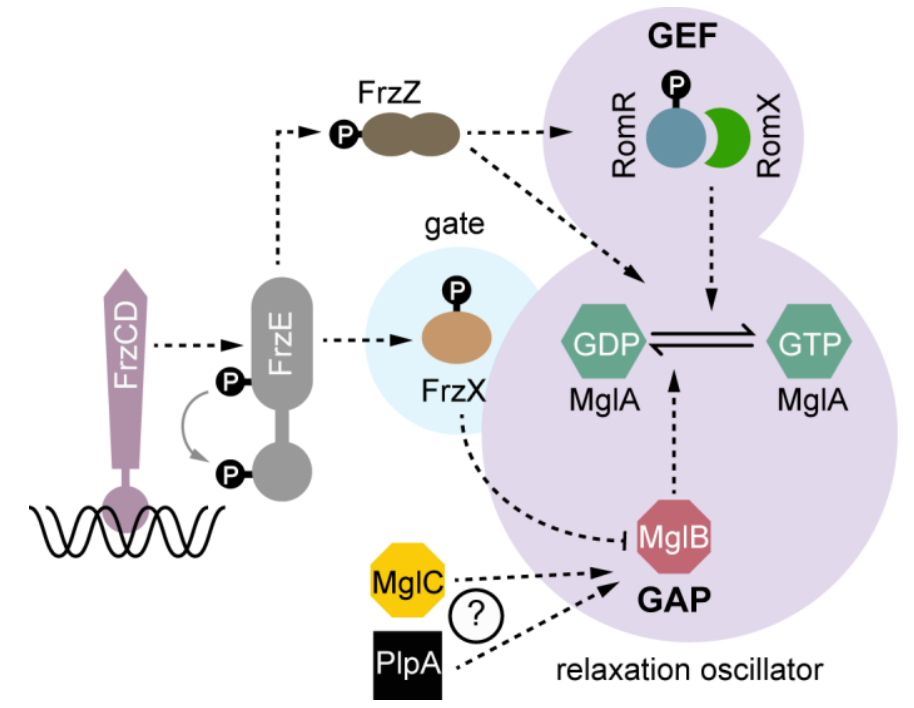

554 